\title{
WAHDAH AL-WUJUD IBN ARABI DALAM IMAJINASI KREATIF HENRY CORBIN
}

\author{
Raha Bistara \\ Universitas Islam Negeri Sunan Kalijaga, Yogyakarta \\ rahabistara07@gmail.com
}

\begin{abstract}
Abstrak
Artikel ini bertujuan untuk mengungkap gagasan wabdah al-wujud Ibn Arabi dalam bingkai imajinasi kreatif Henry Corbin. Hal ini berangkat dari fakta bahwa wabdah al-wujud hingga kini masih menjadi perdebatan di kalangan para pemikir filsafat Islam. Ada yang menyebutkan wahdah al-wujud sama dengan panteisme dan panenteisme ada juga yang mengatakan itu tidak dengan keduanya. Dengan metode kualitatif deskriptif, dengan data-data kepustakaan, kajian ini menunjukkan bahwa imajinasi aktif yang kreatif (imajinasi teofanik) adalah wujud Ilahi mengungkapkan diri-Nya, menunjukan diri-Nya, kepada diri-Nya dengan membedakan diri-Nya dengan wujud-Nya yang tersembunyi. Penciptaan ini sama juga dengan penampakan Tuhan (teofani, tajalli Ilahi). Dalam penciptaan ini tidak ada konsep creation ex nibilo (penciptaan yang keluar dari ketiadaan), penciptaan ini sudah ada wujud dari Tuhan itu sendiri melalui proses tanaffus. Imajinasi kreatif sebagai teofanik merupakan suatu proses penciptaan bukan dari ketiadaan atau sesuatu yang berbeda dari diri-Nya sendiri, melainkan dari wujud fundamental-Nya yang tersembunyi dalam wujud-Nya sendiri tanpa adanya imajinasi yang kreatif sulit untuk mewujudkan Tuhan di tengah kehidupan manusia.
\end{abstract}

Kata Kunci: Wabdah al-Wujud, Imajinasi Kreatif, Imajinasi Teofanik

\begin{abstract}
This article aims to show the idea of wabdah al-mujud Ibn Arabi in the frame of Henry Corbin's creative imagination. Wabdah al-wujud until now is still being debated among philosophers. Some of them say wabdah al-wujud is the same as pantheism and panenteism and some say its not with both. With a descriptive qualitative method and based on library research, this study shows that creative imagination (theophysical imagination) is a form of God revealing himself, showing himself, to himself by distinguishing himself with its hidden existence. This creation is the same as the appearance of God (tajalli ilahi). In this creation there is no concept of creation ex nibilo (creation out of nothing), this creation already existed from God itself through the tanaffus process. Creative imagination as a theophanic is a process of creation not of nothing or something different from Himself, but from His fundamental form that is hidden in His own form without the existence of a creative imagination that is difficult to realize God in the midst of human life.
\end{abstract}

Keyword: Wabdah al-Wujud, Creative Imagination, Teophanic Imagination 


\section{Pendahuluan}

Tasawuf telah memberikan sumbangan yang sangat besar dalam kehidupan spiritual dan khasanah intelektual Islam. Pengaruh tasawuf tidak hanya saja pada golongan elite agama, tetapi menjangkau seluruh lapisan masyarakat dari lapisan paling bawah sampai lapisan paling atas. Tasawuf telah mempengaruhi sikap hidup, moral, dan tingkah laku masyarakat. Ia telah mempengaruhi kesadaran estetik, sastra, filsafat, pandangan hidup dan paling mutahir adalah mempengaruhi dunia sains (psikologi).

Dalam perjalanan sejarahnya, tasawuf tidak luput dari kecurigaan dan kecaman yang keras dari golongan Islam ortodoks. Konflik yang timbul di antara pro dan kontra dengan ajaran tasawuf bisa dilukiskan sebagai konflik antara ahli tasawuf dan ahli fiqh, konflik antara ahli syari'at dan ahli hakikat, konflik antara penganut ajaran esoterik (batini) dan penganut ajaran eksoterik (zabir). Konflik antara kedua golongan ini tidak dapat dihindarkan lebih-lebih ketika munculnya gerakan tasawuf Falsafi. ${ }^{1}$ Gerakan ini dipelopori oleh Abu Yazid al-Bistami (w. 261/875) dengan ajaran ittihad, kemudian ajaran bulul yang dipopulerkan oleh Husayn ibn Mansur al-Hallaj (w. 309/922) dan mencapai puncaknya dengan ajaran wahdah al-wujud oleh Muhyi al-Din ibn al-Arabi (w. 638/1240).

Doktrin wabdah al-wujud sebenarnya tidak dibuat oleh Ibn Arabi sendiri melainkan murid muridnya yang fanatik terhadap Ibn Arabi, di antaranya Shadr al-Din Qunawi (606 H/1210 M), Afif al-Din al-Tilimsani (690 H/1291 M), Sa'd al-Din Hammuyah (649 H/1252 M) dan lain sebagainya. Adapun Ibn Arabi sendiri, sekalipun tidak pernah menggunakan istilah wahdah al-wujud, dia dianggap sebagai pendiri doktrin wabdah al-wujud karena ajaran-ajarannya mengandung ide wahdah al-wujud. ${ }^{2}$

Banyak literatur yang mengartikan atau disinonimkan istilah wabdah al-wujud dengan "panteisme". Istilah ini secara tidak langsung memperkuat anggapan bahwa Ibn Arabi seorang yang mengajarkan paham panteisme. Para pakar berbeda penafsiran tentang wahdah al-wujud, ada yang sependapat bahwa wabdah al-wujud itu sama dengan panteisme, ada juga yang tidak sepakat, bahkan ada juga yang memberikan pengertian tersendiri mengenai wabdah al-wujud.

\footnotetext{
${ }^{1}$ Dalam pembagiannya tasawuf dibagi dalam tiga bagian yakni tasawuf Akhlaki, tasawuf Irfani, dan tasawuf Falsafi. Tasawuf Falsafi yakni tasawuf yang bercampur dengan ajaran filsafat, berkompromi dengan term-term filsafat yang maknanya disesuaikan dengan tasawuf. Tasawuf Akhlaki adalah tasawuf yang berorientasi pada perbaikan ahlak, mencari hakikat kebenaran dan mewujudakan manusia yang dapat makrifat kepada Alloh dengan metode-metode tertentu. Tasawuf Irfani adalah tasawuf yang berusaha menyikap hakikat kebenaran yang diperoleh tidak melalui logika tetapi melalui pemberian Tuhan (maubibab).

${ }^{2}$ Kautsar Azhari Noer, Ibn Al-Arabi, Wabdat Al-Wujud Dalam Perdebatan (Jakarta: Paramadina, 1995). 35.

3 Antara paham wabdah al-wujud dan panteisme, di samping memiliki persamaan juga perbedaan. Dalam panteisme alam adalah Tuhan dan Tuhan adalah alam, sedangkan wahdah al-wujud alam bukan Tuhan, tetapi bagian dari Tuhan. Karena itu, dalam wahdah al-wujud alam dan Tuhan tidak identik, sedangkan dalam panteisme identik. Lihat Amsal Bakhtiar, Filsafat Agama (Depok: Rajawali Press, 2015). 94.
} 
Kautsar Azhari Noer mengatakan wahdah al-wujud bukan panteisme karena kedua hal tersebut tetap berbeda dan tidak setara. Karena itu, mempersamakan wabdab al-wnjud dengan panteisme adalah kesimpulan yang keliru, terburu, dan menyesatkan. ${ }^{4}$ Kemudian Khudori Soleh yang sepaham dengan Kautsar Azhari Noer mengartikan wahdal al-wrijud bukan sama dengan panteisme karena panteisme segala sesuatu sama dengan alam. Sedangkan alam bukanlah Tuhan dan Tuhan bukanlah alam, keduanya tetap entitas yang berbeda. Karena itu, mempersamakan atau memberi label panteisme atas ajaran wabdah al-wujud Ibn Arabi dapat menyebabkan kesalahpahaman dan menyesatkan. ${ }^{5}$

Sementara itu Samsul Munir Amin ${ }^{6}$ dan Cecep Alba ${ }^{7}$ juga berpendapat bahwasanya wujud Tuhan tidak sama dengan wujud alam. Meskipun di satu sisi, ia terkesan menyamakan Tuhan dengan alam, tetapi di satu sisi lain ia menyucikan Tuhan dari adanya persamaan, dalam artian tidak menyamakan Tuhan dengan alam dan secara otomatis wahdah al-wujud bukanlah panteisme. Sedangkan Harun Nasution menjelaskan wahdah al-wujud sebenarnya yang mempunyai wujud hanya satu, yaitu Tuhan. Wujud selain dari Tuhan adalah wujud bayangan. ${ }^{8}$ Ini menguatkan dengan pendapat-pendapat di atas bahwa wahdah al-wujud tidak sama dengan panteisme atau monisme.

Haidar Bagir memberi ulasan menarik mengenai wabdab al-wujud. Ia mengatakan ketunggalan wujud Ibn Arabi ini tidaklah bersifat panteistik yakni, menggangap segala sesuatu sebagai Tuhan tidak juga monoteistik (ketunggalan Tuhan yang transenden, mengatasi dan sepenuhnya berbeda), melainkan monorealistik. Yakni, menegaskan segala ketunggalan segala ada dan mengada.' Pendapat ini membantah perihal wabdab al-wujud sebagai panteistik atau monoteistik.

Selain Haidar Bagir, Aboebakar Atjeh terlebih dahulu menganggap bahwa wahdah al-wnjud bersifat monorealistik. Ia beranggapan wujud itu adalah intipati dari segala yang ada, dan yang bernama dari segala yang baru itu. Karena semua yang bersifat fana akan binasa, tidak ada baginya wujud yang abadi, meskipun keadaanya aneka rupa dan bilangannya amat banyak segala ciptaan dan keadaan. Melainkan yang kekal adalah tunggal dari pada zat-zat itu sendiri dan tidak dihubungkan melainkan satu tunggal dalam zat yang banyak itu. ${ }^{10}$

4 Noer, Ibn Al-Arabi, Wabdat Al-Wujud Dalam Perdebatan. 214.

5 A. Khudori Sholeh, Filsafat Islam dari Klasik Hingga Kontemporer (Yogyakarta: Ar-Ruzz Media Group, 2015). 209.

${ }^{6}$ Samsul Munir Amin, Ilmu Tasamuf(Jakarta: Teruna Grafica, 2012). 278.

7 Cecep Alba, Tasawuf Dan Tarekat Dimensi Esoteris Ajaran Islam (Bandung: Remaja Roesda Karya, 2014). 75.

${ }^{8}$ Harun Nasution, Filsafat Dan Mistisisme Dalam Islam (Jakarta: Bulan Bintang, 2014). 77.

${ }^{9}$ Haidar Bagir, Epistemologi Tasawnf (Bandung: Mizan, 2018). 72.

${ }^{10}$ Aboebakar Atjeh, Wasiat Ibn Arabi (Bandung: Sega Arsy, 2016). 60. 
Sementara itu, menurut A.E. Afifi, Ibn Arabi menganut panteisme yang mempunyai suatu bentuk akosmisme dan memandang Ibn Arabi sebagai seorang "panteis sempurna". ${ }^{11}$ Fazlur Rahman mengatakan bahwa sistem Ibn Arabi sepenuhnya monistik dan panteistik, di mana ajaran ini berlawanan dengan ajaran Islam ortodoks. ${ }^{12}$ Sedangkan Ibrahim Madkour juga memberi penilai tentang ajaran wahah al-wujud Ibn Arabi bersifat panteistik. ${ }^{13}$

Tuduhan bahwa doktrin wahdah al-wujud dapat diberi label "panteisme", "monisme", "monism ontologis", "monisme eksistensialis", "monism pantaistik“, dan semacamnya ditolak dengan tegas oleh salah satu seorang sarjana Muslim kontemporer yakni sayyed Hossein Nasr. Ia memandang bahwa istilah - istilah "panteisme", "panenteisme","monisme eksistensialis", dan "mistisisme natural" tidak dapat dipakai untuk mendiskripsikan doktrin wabdah al-wujud. Tuhan menurut doktrin ini adalah transenden terhadap alam, sekalipun alam dalam tingkatnya sebagai yang real tidak dapat sepenuhnya lain dari Tuhan. Segala sesuatu di alam ini adalah penampakannya. ${ }^{14}$

Bersamaan dengan hal itu, salah satu filsuf Perancis Henry Corbin menyangkal pemakaian istilah monisme dan panteisme untuk menyebut doktrin wahdah al-wujud Ibn Arabi. Ia mengusahakan interpretasi nonpanteistik dan nonmonistik tentang pemikiran Ibn Arabi. Ia juga mengatakan bahwa istilah monisme tidak sesuai untuk mendiskripsikan doktrin wabdah al-wujud Ibn Arabi. ${ }^{15}$

Perbedaan pendapat mengenai pendeskripsian doktrin wabdah al-wujud Ibn Arabi, seperti dipaparkan di atas menggugah pertanyaan-pertanyaan. Benarkah Ibn Arabi seorang panteis ? Jika tidak, apa kekeliruan pendapat bahwa Ibn Arabi adalah seorang panteis disebabkan kekeliruan memahami wabdah al-wujud? Melihat pertanyaan-pertanyaan tersebut maka di era modern ini manusia berpikir lebih komprehensif untuk menjawab itu dengan menyatukan antara dunia tasawuf dan dunia sains (psikologi).

Dalam pandangan Franz Magnis Suseno masyarakat modern adalah masyarakat yang rasionalis, materialis, dan individualis. Manusia modern mendasarkan diri pada realitas inderawi yang tak terbantah daripada sebuah spekulasi-spekulasi spiritual menurutnya sering kosong belaka, atau merupakan pelarian realitas. Modernitas membuat perubahan paradigma, yaitu terjadinya pergeseran dari budaya ekspresif di mana nilai-nilai religius dan estetik bergeser ke budaya progresif

11 A.E. Afifi, Filsafat Mistis Ibn 'Arabi, ed. Sahrir Mawi dan Nandi Rahman (Jakarta: Gaya Media Pratama, 1989). 54.

${ }^{12}$ Fazlur Rahman, Islam, ed. Ahsin Mohammad (Bandung: Pustaka, 2003). 210.

13 Ibrahim Madkour, Aliran Dan Teori Filsafat Islam, ed. Yudian Wahyudi Asmin (Jakarta: Bumi Aksara, 2004). 110.

14 Sayyed Hossein Nasr, Tiga Madz̧ab Utama Filsafat Islam (Yogyakarta: IRCiSoD, 2014). 193 - 194.

${ }^{15}$ Henry Corbin, Imajinasi Kreatif Sufisme Ibn Arabi, ed. Moh. Khozim dan Suhadi (Yogyakarta: LkiS, 2014). 285. 
dengan dominasi nilai-nilai rasionalitas dan ekonomi. ${ }^{16}$ Hal inilah sebenarnya yang mendasarkan pemikiran masyarakat modern untuk memisahkan antara bidang sakral (ruh) dan bidang duniawi (material) dalam kehidupan sehari-hari. ${ }^{17}$

Membahas kesatuan wujud dalam masa ini, tidak lepas dari dunia imajinasi. Dalam Kamus Filsafat, imajinasi atau imagination adalah kemampuan menghidupkan kembali atau khususnya penciptaan imajinasi dalam mata jiwa. Namun, yang lebih umum, kemampuan untuk mencipta dan memunculkan situasi-situasi yang memungkinkan, mengkombinasikan pengetahuan lewat caracara yang tidak lazim atau menemukan eksperimen-eksperimen berpikir. ${ }^{18}$ Sartre juga menjelaskan bahwa imajinasi adalah sebuah tindakan yang mengangankan sebuah objek yang tidak hadir atau sebuah objek yang tidak eksis dalam sebuah benda, dengan menggunakan kandungan psikis dan mental yang hadir hanya sebagai sebuah "wakil yang logis" dari objek yang diangankan. ${ }^{19}$

Dalam melakukan imajinasi, manusia demi mengetahui kesatuan wujud tentunya mereka melakukan sebuah penciptaan melalui dunia imajinasi mereka. Penciptaan bisa dikatakan sebagai penampakan (Epifani, tajalli), yakni peralihan dari potensi atau kegaiban menuju keadaan yang bersinar, manifestasi, yang terungkapkan, dengan begitu penciptaan adalah suatu aksi ilahiah, imajinasi primordial. ${ }^{20}$ Terbentuknya sebuah ciptaan melalui imajinasi terkait penciptaanya tentunya tidak serta merta begitu saja muncul dengan mudah dalam dunia imajinasi. Harus ada proses yang berjalan untuk menghasilkan sebuah ciptaan yang dianggpanya sebagai yang haqq, dengan ini timbulah proses yang namanya "Imajinasi Kreatif" atau creative imagination. ${ }^{21}$

Imajinasi kreatif sebagai mediatrik antara sang pencipta turun ke mahluk atau mahluk ke sang pencipta. Secara hakiki imajinasi kreatif organ untuk penampakan Tuhan atau biasa disebut sebagai teofani. Teofani secara primordial berarti Tuhan menampakan dirinya melalui sifat - sifat yang dapat dihayati oleh ciptaan-Nya dan ini berarti Imajinasi Kreatif sebagai wadah untuk menciptakan sebuah ciptaan. Gagasan Imajinasi Kreatif ini di buat oleh Henry Corbin hal yang menarik dari Corbin yakni dia seorang orientalis yang fokus dalam kajian israqiyah yang dicetuskan oleh Suhrawardi dan sekaligus ia mempelajari pemikiran Ibn Arabi. Kata Corbin antara Hallaj, Suhrawardi, dan Ibn Arabi tiga serangkaian herarkis pemikiran yang tidak bisa dipisahkan karena saling keterkaitan satu dengan yang lainnya.

\footnotetext{
16 Franz Magnis Suseno, Pijar-Pijar Filsafat (Yogyakarta: Kanisius, 2005). 140.

${ }^{17}$ Kazuo Shimogaki, Kiri Islam, Antara Modernisme Dan Postmodernisme, ed. Imam Aziz (Yogyakarta: LkiS, 1993). 32.

18 Simon Blackburn, Kamus Filsafat (Yogyakarta: Pustaka Pelajar, 2008). 433.

19 Jean Paul Sartre, Psikologi Imajinasi, ed. Silvester G Syukur (Yogyakarta: Narasi dan Poestaka dan Promethea, 2016). 42.

${ }^{20}$ Corbin, Imajinasi Kreatif Sufisme Ibn Arabi. 255

${ }^{21}$ Creative Imagination adalah sebuah pola atau ide - ide yang menyertai pemecahan suatu masalah atau pengembangan suatu bentuk baru. Lihat. C.P Chaplin, Kamus Lengkap Psikologi (Jakarta: Raja Grafindo Persada, 1993). 117.
} 
Berangkat dari penjelasan di atas, kajian ini bertujuan untuk membahas gagasan wabdah alwujud Ibn Arabi dalam bingkai imajinasi kreatif Henry Corbin. Metode yang digunakan adalah library research yang mengeksplorasi data-data kepustakaan terkait dengan tema kajian. Kajian ini diharapkan memberikan sumbangan pemikiran, khususnya dalam pengembangan keilmuan filsafat islam dan tasawuf.

\section{Biografi Intelektual Ibn Arabi}

Ibn Arabi, nama lengkapnya Muhammad bin 'Ali Muhammad bin Ahmad bin 'Abd Allah al-Hatsmi Ibn al-Arabi. ${ }^{22}$ Ia lahir di Murcia, Spanyol bagian tenggara pada tanggal 17 Ramadhan 560 H/ 28 Juli 1165 M, pada masa pemerintahan Ya'kub Yusuf I (1163-1184 M) dari Dinasti Muwahhidun (1121-1269 M). Pada masanya nama Ibn Arabi yang terkenal dalam masyarakat Spanyol ada dua, yang satu ahli sufi dan satunya lagi sebagai ahli hadis ia bernama lengkap Abu Bakar Muhammad Ibn Abdillah Ibn Arabi Al-Ma'afiri (1076-1148 M) yang kemudian menjadi hakim di Sevilla. ${ }^{23}$

Ibn Arabi berasal dari keturunan ningrat Arab yang saleh. Ayah dan tiga pamannya dari jalur ibu adalah sufi yang mashur, ia sendiri menjadi seorang sufi yang saleh dengan mendapat gelar sebagai Mubyi al-Din (penghidup agama) dan al-Syaikh al-Akbar (Doktor Maximus). Pendidikan Ibn Arabi dimulai di Sevilla, ketika ayahnya menjabat di istana dengan pelajaran yang umum pada saat itu, yakni al-Quran, hadis, fiqh, teologi, tasawuf, dan filsafat skolastik. ${ }^{24}$

Selama menetap di Sevilla, Ibn Arabi muda sering melakukan kunjungan ke berbagai kota di Spanyol, untuk berguru dan bertukar pikiran dengan para tokoh sufi, filosof, ahli hukum, ahli hadis, dan para intelektual lainnya. Akan tetapi, situasi religio -politis tidak mendukung bagi Ibn Arabi untuk tinggal lama di Spanyol atapun di Afrika Utara sehingga pergi ke Makkah (1201 M). Ketika salah satu perjalanannya di Cordoba, ia bertemu dengan Ibn Rusyd ${ }^{25}$ dalam pertemuan yang maha penting. Dianggap penting, karena dalam pertemuan itu dua kepribadian yang melambangkan dua jalan yang akan diikuti pada masa selanjutnya oleh dunia Kristen dan Islam. ${ }^{26}$

Pada tahun 589 H/1202 M dengan ziarah ke Timur, periode baru bermula dalam kehidupan Ibn Arabi. Di sini ia mendapatkan ilham untuk menulis karya monumentalnya, al-

22 Ali Mahdi Khan, The Elements of Islamic Philosophy (Lahore: Sh. Muhammad Ashraf, 1973). 147.

23 Sholeh, Filsafat Islam dari Klasike Hingga Kontemporer. 198.

${ }^{24}$ Noer, Ibn Al-Arabi, Wabdat Al-Wujud Dalam Perdebatan. 18.

${ }^{25}$ Ibn Rusyd, nama lengkapnya adalah Abul Walid Muhammad bin Ahmad bin Muhammad bin Ahmad bin Rusyd. Dilahirkan di Kordoba tahun 520 H/ 1126 M di tengah - tengah keluarga yang kaya harta dan ilmu. Ia adalah seorang filosof yang beraliran Aristotelian dan danggap sebagai Aristoteles Islam, karena dia adalah satu-satunya filosof muslim yang sangat menguasai filsafat Aristoteles. Lihat Ismail Asy-Syarafa, "Ibn Rusyd," Ensiklopedia Filsafat (Khalifa, 2005). 8.

${ }^{26}$ Sayyed Hossein Nasr, Three Muslim Sages; Avicenna-Subrawardi-Ibn Arabi (New York: Caravan Book, 1993). 
Futuhat al-Makkiyah (Wahyu-wahyu Makkah) dalam 560 jilid dan menulis kitabnya yang lain, Fushush al-Hikam (Faset-faset Ilmu Pengetahuan Ilahi) dan ia memperoleh kemasyhuran tertinggi. Futuhat, seperti yang dijelaskan oleh penulisnya, didektekan oleh Tuhan melalui malaikat pemberi ilham, sedangkan Fusus, sebuah buku dengan dua puluh sembilan bab mengenai ilmu kenabian, diilhami oleh nabi. ${ }^{27}$

Pada tahun 609 H/ 1211 M, ia bertemu dengan Sufi terkenal Syihab al-Din 'Umar Suhrawardi, nama yang sama dengan Pendiri Iluminasi, yang memang sering terjadi kesalahan sebutan dengannya. ${ }^{28}$ Periode ini ia juga menyelesaikan karya monumentalnya, al-Futuhat alMakkiyah (Wahyu-wahyu Makkah), yang berisi catatan spiritual selama tiga puluh tahun dari periode kehidupannya yang penuh berarti. Sang maestro akhirnya meninggal dunia di Damaskus pada 22 Rabi al-Tsani 638 H/ November 1240 M pada usia 78 tahun dengan meninggalkan tanda tak terhapuskan di atas keseluruhan kehidupan spiritual Islam. Ia dikebumikan di Salihiyah, di kaki Gunung Qasiyun, bagian utara Damaskus, sebuah tempat yang dimulaikan sebelum ia dikebumikan di sana, sebagai tempat yang disucikan oleh seluruh nabi.

\section{Wahdah al-Wujud Menurut Ibn Arabi}

Wabdah al-wujud biasanya dihubungkan dengan Ibnu Arabi, karena tokoh ini dianggap sebagai pendirinya. Kajian ilmiah tentang wahdah al-wujud ini tidak dipersoalkan oleh sarjana-sarjana muslim maupun para orientalis, akan tetapi penyelidikan tentang istilah wabdah al-wujud dilakukan belakangan jauh setelah Ibn Arabi wafat. Istilah wabdah al-wujud tidak diciptakan oleh sufi terkenal dari Mursia ini. Ibnu Arabi tidak pernah menggunakan istilah ini dan tidak pernah ditemukan dalam karya- karyanya. ${ }^{29}$

Walaupun Ibnu Arabi tidak pernah menggunakan istilah wabdah al-wujud, tetapi ia dianggap sebagai pendiri doktrin wabdah al-wujud karena ajaran-ajarannya mengandung ide wabdah al-wujud. Bukti ide tersebut dari kutipan pernyataannya: "Tiada yang tampak dalam wujud melalui wnjud kecuali al-Haqq, karena wujud adalah al-Haqq, dan Dia adalah satu". "Selanjutnya Ibnu Arabi menyatakan bahwa, entitas wujud adalah satu tapi hukum-hukumnya beraneka. Dia (Tuhan) adalah Esa dalam

${ }^{27}$ Annemarie Schimmel dan Sapardi Djoko Damono, Dimensi Mistik dalam Islam (Jakarta: Pustaka Firdaus, 2000). 336.

28 Ibn Arabi memiliki hubungan dengan banyak tokoh terkenal pada masanya, di antaranya Suhrawardi dan penyair Persia Awhad al-Din al-Kirmani. Ia bertatap muka secara personal dengan tokoh-tokoh tersebut dan tokoh lainnya dengan cara lain, seperti Ibn Farid, Sa'd al-Din al-Hammuyah, dan Fakhr al-Din al-Razi, tokoh yang pernah terlibat surat menyurat dengannya. Surat Ibn Arabi kepada Fakr al-Din yang menasehatinya agar meletakan proses belajar formalnya dan berusaha memperoleh Gnosis.

${ }^{29}$ Noer, Ibn Al-Arabi, Wabdat Al-Wujud Dalam Perdebatan. 34.

${ }^{30}$ Muhyi al-Din Ibn 'Arabi, Al-Futuhat Al-Makiyah (Beirut: Dar al-Kutub al-'Ilmiyah, 1999). 198. 
wujud karena semua yang mungkin yang dapat dilihat, disifati dalam keadaan ini dengan ketiadaan. Semua yang mungkin itu tidak mempunyai wujud meskipun tampak bagi yang melihat. ${ }^{31}$ Al-Haqq dan Al-Khalq

Kata al-Haqq mempunyai beberapa pengertian yang berbeda dalam konteks-konteks yang berbeda pula. Pengertian al-Haqq yang dibicarakan di sini dibatasi dalam konteks hubungan ontologis antara al-Haqq dan al-khalq. Al-Haqq adalah Allah, Sang Pencipta, Yang Esa, Wujud dan Wajibul Wujud, sedangkan al-khalq adalah alam, makhluk, yang banyak, al-maujuddat dan almumkinunat. $^{32}$

Al-Haqq adalah maijud melalui Zat-Nya dan untuk Zat-Nya. Wujud-Nya mutlak tanpa terbatasi oleh pihak lain. Dia bukanlah akibat dari apapun dan tidak menjadi sebab untuk apapun, tetapi Dialah yang menciptakan segala akibat dan sebab-sebab. Satu-satunya wrijud adalah Allah, tidak ada wujud selain wujud Allah. Dengan kata lain, wujud dalam pengertian hakiki hanya milik alHaqq, segala sesuatu selain al-Haqq tidak memiliki wujud. Karena itu wujud Hanya satu, yaitu alHaqq.

Sedangkan alam adalah penampakan diri (tajalli) al-Haqq dan dengan demikian segala sesuatu dan segala peristiwa di alam ini adalah entifikasi (ta'ayyun) al-Haqq. Karena itu, baik Tuhan maupun alam, keduanya tidak bisa dipahami kecuali sebagai kesatuan antara kontradiksikontradiksi ontologis. Alam semesta adalah maijud melalui Allah, bukan melalui dirinya sendiri atau untuk dirinya sendiri. Wujudnya terbatas dengan wujud al-Haqq dalam diri-Nya, sehingga wujud alam semesta tidak mungkin ada sama sekali kecuali melalui wijud al-Haqq. ${ }^{33}$

Tajalli al-Haqq

Wabdah al-wujud Ibn Arabi berkaitan dengan konsep tajalli (penampakan diri) al-Haqq. Di atas telah dijelaskan, Tuhan menciptakan alam agar dapat melihat diri-Nya. Dia mengenal diri-Nya memperlihatkan diri-Nya melalui alam. Al-Haqq melakukan tajalli dalam setiap sesuatu sesuai dengan "kesiapan" setiap sesuatu itu. Tingkat kemampuan setiap sesuatu untuk menerima tajalli ditentukan oleh "kesiapan" yang dimilikinya. Tetapi kesiapan masing-masing dari egala sesuatu dalam alam untuk menerima tajalli berbeda satu sama lain.

Tajalli yang dimaksudkan Ibn Arabi memang benar bahwa wujud Allah hanya satu, tapi penampakkan-Nya banyak. Sifat-Nya juga ada pada selainnya, misal mendengar, melihat dan sebagainya. Tetapi perlu dikethui bahwa sifat yang dimiliki Allah berbeda dengan sifat yang dimiliki manusia. Sifat yang dimiki Allah kekal kerena Dia adalah raja absolut yang menciptakan segala yang ada di bumi. Sedangkan manusia hanya makhluk ciptaan Allah yang jauh dari kesempuraan dan

\footnotetext{
${ }^{31}$ Muhyi al-Din Ibn 'Arabi, Al-Futuhat Al-Makizyah. 30

${ }^{32}$ Afifi, Filsafat Mistis Ibn 'Arabi. 27.

${ }^{33}$ Noer, Ibn Al-'Arabi Wahdat Al-Wujud Dalam Perdebatan. 49.
} 
jauh berbeda dengan yang menciptakan.

Tanzih dan Tasybih

Kata tanzih berasal dari kata kerja nazzaha, secara harfiah berarti menjauhkan atau membersihkan sesuatu yang mengotori, sesuatu yang tidak murni. Adapun tasybih berasal dari kata kerja syabbaha, yang secara harfiah adalah merupakan atau menganggap sesuatu serupa dengan yang lain.

Menurut antropomorphis pernyataan bahwa Tuhan "mendengar" atau "melihat" atau "punya tangan", dan sebagainya, nyatanya menurut pemahaman Ibnu 'Arabi tidak dimaksudkan sebagai Tuhan memiliki "alat pendengar" atau "alat penglihat" atau "punya tangan" dan sebagainya, melainkan Ia itu immanen (tasybih) dalam semua pendengaran, penglihatan atau mempunyai tangan ${ }^{34}$

Ibn Arabi dengan tegas menolak antropomorfisme dan korporealisme dalam pengertian di atas. Dalam bentuk apapun Tuhan telah menggambarkan diri-Nya sendiri di dalam al-Quran di mana kedua aspek transendensi dan immanensi harus diperhatikan. Al-Quran mengatakan bahwa Tuhan punya tangan dan kaki, dan sebagainya. Ini kata Ibn Arabi adalah memang benar dan bukan dalam pengertian antropomorfis bahwa ia punya tangan dan kaki yang sebanding dengan yang dipunyai manusia, tapi dalam pengertian bahwa Ia itu pada hakikatnya mempunyai tangan dan kaki-kaki dari semua yang punya tangan dan kaki-kaki.

Tanzih dan tasybih menurut Ibn Arabi harus dipadukan sebab keduanya adalah satu kesatuan yang tidak dapat dipisahkan, apalagi dipertentangkan. Tanæih menunjukan aspek "keterbatasan" pada-Nya. Dilihat dari segi zat-Nya, Tuhan adalah munazzah bersih dari dan tidak dapat diserupakan dengan alam dan ketidaksempurnaannya, jauh dari dan tinggi di atas segala sifat dan segala keterbatasan dan keterikatan. Dalam pengertian ini, Tuhan tidak dapat diketahui, tidak dapat ditangkap, tidak dapat dipikirkan dan tidak dapat dilukiskan. Dia adalah transenden. Satusatunya sifat yang berlaku bagi-Nya adalah "kemutlakkan".

Penafsiran Ibn Arabi tentang tanzih dan tasybih sesuai dengan doktrin ontologisnya tentang wabdah al-wujud yang tertumpu pada perumusan ambigu: "Dia dan bukan Dia" sebagai jawaban atas persoalan apakah alam identik dengan Tuhan. Dari uraian di atas dapat disimpulkan bahwa wahdah al-mujud menurut Ibnu 'Arabi adalah wujud yang ada hanya satu yaitu Tuhan, sedangkan yang lainya selain wijud Allah adalah tajalli-Nya (penampakan-Nya).

\section{Imajinasi Kreatif (Creative Imagination) Henri Corbin}

Konsep tentang imajinasi, penengah antara pikiran dan wujud menjasadnya pikiran dalam bayangan serta hadirnya bayangan dalam wujud adalah konsep terpenting yang memainkan peran

${ }^{34}$ Affifi, Filsafat mistis Ibnu' 'Arabi. 38. 
terbesar dalam renaisans dan kita temui dalam filsafat romantisisme. Imajinasi menjadi tolak ukur penting dalam berpikir untuk menciptakan suatu kreasi yang baru, di mana dianggap sebagai pembeda antara satu dengan yang lainnya.

Imajinasi sebagai potensi magis yang kreatif dan melahirkan dunia inderawi, menghasilkan roh dalam berbagai bentuk dan warna, gagasan mengenai dunia magia divina yang diimajinasikan oleh Tuhan merupakan doktrin kuno melaui kata imago dan magia, yang ditemukan oleh sang novelis dan filsuf berkebangsaan Jerman yakni melalui Fitche. Akan tetapi, imagination tidak boleh dikacaukan dengan fantasi. Imajinasi dan fantasi sangat jauh berbeda, karena imajinasi adalah kerja pikiran tanpa fondasi dalam tabiatnya, sedangkan fantasi adalah batu pijakan orang gila.

Pada umumnya imajinasi merupakan tindak mengangankan sebuah objek yang tidak hadir atau objek yang tidak eksis sebagai sebuah benda. Dengan menggunakan kandungan psikis dan mental yang hadir hanya sebagai sebuah 'wakil yang logis' dari objek yang diangankan. ${ }^{35}$ Daya cipta di sini harus berjalan ketika ingin menghadirkan sebuah objek yang diangankan dengan penggunaan psikis dan mental, dan tindakan pencipta menjadi penentu soal keterwujudan objek yang diimajinasikan. Tidak ada gerakan tindak penciptaan maka tidak ada ciptaan yang terwujud, serta objek yang diangankan dengan penggunaan psikis dan mental tentunya juga tidak ada.

Imajinasi Kreatif berarti perwujudan Tuhan dengan segala bentuk-Nya yang diciptakan oleh diri-Nya dengan perantara mahluk yang berakal. Perwujudan ini dengan perantara akal aktif dengan bayangan yang kabur mewujudkan sebuah ciptaan yang tercipta. Artinya pencipta ciptaan (khaliq mabluk) ini berarti wujud ilahi merupakan sesuatu yang tersembunyi dan yang tersingkap. Dia adalah yang pertama (al-Awnal) dan yang terakhir (al-Akbir). Perwujudan ciptaan ini semua diatur oleh-Nya, karena Dia yang menentukan segala kehidupan yang ada di dunia.

Penciptaan yang berkelanjutan, selalu diperbarui dari waktu ke waktu dan Imajinasi teofanik tanpa henti. Dengan kata lain ide mengenai bergantinya berbagai penampakan (theopanies, tajalliyat) menyebabkan bergantinya wujud secara berkesinambungan. ${ }^{36}$ Wujud Tuhan akan selalu terciptakan secara berkesinambungan tanpa henti, karena Tuhan ingin memperlihatkan dirinya dalam berbagi bentuk, berbagai penampakan kepada ciptaan yang diciptakan oleh diri-Nya. Maka penciptaan akan terus berjalan dan bersifat pembaharuan sebab Tuhan memperlihatkan diri-Nya sesuai sifat-sifat yang ada dengan keinginan diri-Nya sendiri.

\section{Imajinasi Kreatif Sebagai Teofani}

Pada mulanya wujud Tuhan hanyalah satu, ia tidak dikenai suatu syarat. Kita mengetahui hal ikhwal bahwa Ia merasa sedih atas kesendirian primordial yang membuat Ia merindu untuk

\footnotetext{
35 Jean-Paul Sartre dan Silvester G Syukur, Psikologi Imajinasi. 42.

${ }^{36}$ Henry Corbin, Imajinasi Kreatif Sufisme Ibn 'Arabi. 255.
} 
disingkapkan dalam bentuk mahluk-mahluk yang akan memanifestasikan Dia untuk diri-Nya sendiri, seperti halnya Dia memanifestasikan diri-Nya untuk mereka. ${ }^{37}$ Pada dasarnya Tuhan ingin menyikapkan diri-Nya dalam bentuk semua mahluk yang ada di bumi ini dan penyikapan yang paling sempurna berupa bentuk manusia.

Kesedihan yang dialami oleh sang Ilahi akan turun dalam bentuk nafas illahi (Tanaffus) berupa kasih (Rahmah) dan peng-ada-an (ijad). Yang ada dalam alam misteri ini merupakan bentuk kasih dari Wujud Ilahi untuk diri-Nya sendiri, yakni untuk nama-nama-Nya sendiri. Dengan istilah lain cintalah yang menyebabkan penyikapan yang mengakibatkan hasrat yang bergelora berupa cinta. Hasrat yang bergelora ini diredakan oleh Nafas Ilahi (Tanaffus).

Dengan menemukan misteri wujud dengan pengalaman wujudnya sendiri, sang teosof harus menghindari pertentangan teologis antara Ens inscretum dan ens creatum yang dihasilkan dari ketiadaan, suatu pertentangan yang memunculkan keraguan tentang apakah nisbah Summun Ens dan ketiadaan yang Dia gunakan untuk memunculkan mahluk-mahluk yang benar-benar telah dirumuskan secara shahih. Kesedihan bukanlah hak istimewa semua mahluk, dia ada pada pencipta sendiri, malahan justru itulah yang menjadi kesimpulan kita membuat wujud primordial sebagai suatu wujud yang berdaya cipta itulah rahasia kerativitas-Nya.

Penciptaan memancarkan bukan dari ketiadaan, dari sesuatu yang berbeda dari diri-Nya sendiri, bukan Dia, melainkan dari wujud fundamental-Nya yang tersembunyi dalam wujud-Nya sendiri. Jadi kata Tanaffus juga memiliki arti "bersinar", seperti muculnya fajar. ${ }^{38}$ Penciptaan yang dilakukan oleh sang pencipta melalui nafas Ilahi diibaratkan seperti cahaya di pagi hari yang memancar, tetapi pancaran itu bukan dari diri-Nya sendiri melainkan dari wujud yang bersifat fundamental yang tersembunyi dalam wujud.

Pada hakikatnya penciptaan adalah pengungkapan wujud Tuhan, pertama-tama pada diriNya sendiri, suatu pemendaran (luminiscene) yang terjadi di dalam diri-Nya. Penciptaan sama juga dengan Penampakan Tuhan (teofani, tajalli Ilabi). Dalam penciptaan ini tidak ada konsep yang namanya creation ex nibilo (penciptaan yang keluar dari ketiadaan), penciptaan ini sudah ada wujud dari Tuhan itu sendiri melalui proses Tanaffus. Nafas Ilahi menghembuskan Nafas Ar-Rabman atau Nafas Rabmani, yakni nafas kasih yang meng-ada-kan. Nafas ini menghasilkan segenap masa pengada-an primordial halus yang diistilahkan sebagai awan (ama).

Imajinasi Teofanik atau Imajinasi Kreatif pada hakikatnya Wujud Ilahi ingi mengungkapkan diri-Nya, menunjukan diri-Nya kepada diri-Nya dengan membedakan diri-Nya dengan wujud-Nya yang tersembunyi, dengan memanifestasikan virtualitas nama-nama-Nya

${ }^{37}$ Henry Corbin, Imaj̈nasi Kreatif Sufisme Ibn 'A rabi. 251.

${ }^{38}$ Henry Corbin, 252. 
dengan berpasang-pasangan di mana prototipe mereka yang tersembunyi dalam zat-Nya. Imajinasi Teofanik dan kasih yang meng-ada-kan adalah konsep yang sama, yakni menyatakan realitas yang sama berupa wujud Ilahi dari-Nya diciptakan segala bentuk (al-haqq al-mabluk bibi kull say). Maksud yang sama dari ungkapannya "Pencipta ciptaan", karena Dia adalah nafas yang dihembuskan dariNya, dan tersembunyi pada-Nya. Sebab itu awan adalah tak kasatmata yang bersifat "esoteris" (batbin), dan Dia adalah ciptaan yang dimanifestasikan (Zhabir).

Dalam pandangan Ibn Arabi "Penciptaan" juga memainkan peran penting sebagai salah satu konsep kunci dalam kreatif Allah. Namun, sebagaimana yang kita lihat, konsep yang paling mendasar dari ontologi Ibn Arabi adalah manifestasi diri, dan alam wujud ujung-ujungnya tidak lain adalah manifestasi sang mutlak, dan tidak ada satu apapun yang terjadi di alam melainkan manifestasi diri-Nya. ${ }^{39}$ Penciptaan yang dilakukan oleh sang pencipta tidak lain sebuah manifestasi diri-Nya agar diri-Nya diketahui oleh mahluk-mahluk yang diciptakan oleh diri-Nya.

Fungsi Imajinasi Aktif atau Imajinasi Teaofanik adalah sebagai perantara mediatriks antara Pencipta dan ciptaan sehingga mewujudkan suatu bentuk yang diinginkan oleh pencipta agar diriNya bisa diketahui oleh ciptaan-Nya. Imajinasi juga berfungsi sebagai "tempat penampakan" wujud-wujud spriritual para malaikat dan roh, tempat di mana mereka memperoleh bentuk dan figur "rupa penampakan" mereka, dan karena di sana konsep-konsep murni (ma'ani) dan data indra (mahsusat) bertemu dan memekar menjadi figur-figur personal yang disiapkan untuk meghadapi drama-drama even-even rohani.

\section{Kesimpulan}

Wabdah al-wujud menurut Ibn Arabi adalah wujud yang ada hanya satu yaitu Allah, sedangkan selain-Nya adalah tajalli (penampakan-Nya). Satu- satunya wujud adalah Allah, tidak ada wujud selain wujud-Nya. Dengan kata lain, wujud dalam pengertian hakiki hanya milik Allah, segala sesuatu selain Allah tidak memiliki wujud.

Sedangkan Imajinasi Aktif yang Kreatif (Imajinasi Teofanik) yakni wujud Ilahi mengungkapkan diri-Nya, menunjukan diri-Nya, kepada diri-Nya dengan membedakan diri-Nya dengan wujud-Nya yang tersembunyi. Penciptaan sama juga dengan Penampakan Tuhan (teofani, tajalli Ilabı). Dalam penciptaan ini tidak ada konsep creation ex nibilo (penciptaan yang keluar dari ketiadaan), penciptaan ini sudah ada wujud dari Tuhan itu sendiri melalui proses Tanaffus. Imajinasi Kreatif sebagai Teofanik yakni suatu proses penciptaan memancarkan bukan dari ketiadaan, dari sesuatu yang berbeda dari diri-Nya sendiri, melainkan dari wujud fundamental-Nya yang tersembunyi dalam wujud-Nya sendiri.

39 Toshihiko Izutsu, Toshibiko Izutsu, Sufism and Taoism: A Comparative Study of Key Philosophical Concepts (Berkeley: University of California Press, 1984). 233. 


\section{Referensi}

Afifi, A.E. Filsafat Mistis Ibn 'Arabi. Edited by Sahrir Mawi dan Nandi Rahman. Jakarta: Gaya Media Pratama, 1989.

Alba, Cecep. Tasawuf Dan Tarekat Dimensi Esoteris Ajaran Islam. Bandung: Remaja Roesda Karya, 2014.

Amin, Samsul Munir. Ilmu Tasawuf. Jakarta: Teruna Grafica, 2012.

Asy-Syarafa, Ismail. "Ibn Rusyd.” Ensiklopedia Filsafat. Khalifa, 2005.

Atjeh, Aboebakar. Wasiat Ibn Arabi. Bandung: Sega Arsy, 2016.

Bagir, Haidar. Epistemologi Tasawnf. Bandung: Mizan, 2018.

Bakhtiar, Amsal. Filsafat Agama. Depok: Rajawali Press, 2015.

Blackburn, Simon. Kamus Filsafat. Yogyakarta: Pustaka Pelajar, 2008.

Chaplin, C.P. Kamus Lengkeap Psikologi. Jakarta: Raja Grafindo Persada, 1993.

Corbin, Henry. Imajinasi Kreatif Sufisme Ibn Arabi. Edited by Moh. Khozim dan Suhadi. Yogyakarta: LkiS, 2014.

‘Arabi, Muhyi al-Din Ibn. Al-Futuhat Al-Makiyah. Beirut: Dar al-Kutub al-'Ilmiyah, 1999.

Izutsu, Toshihiko. Toshibiko Izutsu, Sufism and Taoism: A Comparative Study of Key Philosophical Concepts. Berkeley: University of California Press, 1984.

Khan, Ali Mahdi. The Elements of Islamic Philosophy. Lahore: Sh. Muhammad Ashraf, 1973.

Madkour, Ibrahim. Aliran Dan Teori Filsafat Islam. Edited by Yudian Wahyudi Asmin. Jakarta: Bumi Aksara, 2004.

Nasr, Sayyed Hossein. Three Muslim Sages; Avicenna-Subrawardi-Ibn Arabi. New York: Caravan Book, 1993.

—. Tiga Mad₹̧ab Utama Filsafat Islam. Yogyakarta: IRCiSoD, 2014.

Nasution, Harun. Filsafat Dan Mistisisme Dalam Islam. Jakarta: Bulan Bintang, 2014.

Noer, Kautsar Azhari. Ibn Al-Arabi, Wabdat Al-Wujud Dalam Perdebatan. Jakarta: Paramadina, 1995.

Rahman, Fazlur. Islam. Edited by Ahsin Mohammad. Bandung: Pustaka, 2003.

Sartre, Jean Paul. Psikologi Imajinasi. Edited by Silvester G syukur. Yogyakarta: Narasi dan Poestaka dan Promethea, 2016.

Shimogaki, Kazuo. Kiri Islam, Antara Modernisme Dan Postmodernisme. Edited by Imam Aziz. 
Yogyakarta: LkiS, 1993.

Sholeh, A. Khudori. Filsafat Islam Dari Klasik Hingga Kontemporer. Yogyakarta: Ar-Ruzz Media Group, 2015.

Suseno, Franz Magnis. Pijar-Pijar Filsafat. Yogyakarta: Kanisius, 2005. 